\title{
ГЕОЭКОЛОГИЯ
}

УДК 553.6 (470.54)

\section{Мероприятия по экологической безопасности эксплуатации Селищенского месторождения строительного гипса}

\author{
А.К. Алванян ${ }^{\mathrm{a}}$, Р.Г. Ибламинов ${ }^{\mathrm{a}}$, К.А. Тамоян ${ }^{\mathrm{a}}$, А.А. Согорин \\ арермский государственный национальный исследовательский \\ университет, 614990, Пермь, ул. Букирева, 15. E-mail: iqeon@psu.ru \\ bООО «УралГеоПроект», 614007, Пермь, ул. Революции, 3/7 \\ E-mail: Geo.progekt@yandex.ru \\ (Статья поступила в редакцию 10 апреля 2017 г.) \\ Рассмотрены вопросы охраны почв, земельных ресурсов, атмосферного воздуха, \\ растительного и животного мира, поверхностных и подземных вод и \\ восстановления (рекультивации) нарушенных земель. Разработаны мероприятия \\ по снижению и предотвращению негативного воздействия разработки \\ месторождений полезных ископаемых открытым способом на окружающую \\ среду.
}

Ключевые слова: месторождения гипса, природоохранные мероприятия, рекультивация, Пермский край.

DOI: 10.17072/psu.geol.16.2.185

Гипс - двуводный сульфат кальция $\mathrm{CaSO}_{4} \cdot 2 \mathrm{H}_{2} \mathrm{O}$. Это название используется одновременно для обозначения минерала и породы. Гипс как сырье для получения вяжущего строительного материала известен человечеству уже несколько тысяч лет. Еще египтяне применяли гипсовую штукатурку на стенах склепов, и она использовалась во всех более поздних цивилизациях (Бейтс, 1965). Благодаря своим уникальным свойствам сегодня гипс широко применяется в различных отраслях народного хозяйства (медицина, сельское хозяйство, строительная отрасль и т.д.).

Гипсы Предуралья образовались в результате воздействия подземных вод на ангидриты и представляют собой своеобразную кору выветривания ангидритов, а месторождения гипса относятся к классу остаточных (Даровских, Кудряшов, 2001).

На территории Пермского края имеются большие запасы гипса и ангидрита, есть перспективы по дополнительному их приросту. Согласно минерагеническому районированию Пермского края Селищенское месторождение строительного гипса входит в Предуральскую минерагеническую область (рис. 1). Общие запасы строительного гипса составляют порядка 90 млн т. Гипс и ангидрит, пригодные для строительных целей, представлены в 36 проявлениях и месторождениях, сложенных сульфатными отложениями кунгурского яруса, развитыми в Добрянском, Кунгурском, Кишертском, Октябрьском и Ординском районах (Минерально-сырьевые..., 2006). Разнозернистый гипс разных сортов встречается белой и серой разновидности со всевозможными переходными цветовыми оттенками. Залегание, как правило, близповерхностное, что предопределяет открытый способ отработки.

Селищенское месторождение строительного гипса расположено в Чусовском 
районе Пермского края и приурочено к водораздельной возвышенности между р. Селищной, окаймляющей месторождение с востока и юго-востока, и её правым безымянным притоком (рис. 2). Макси- мальная отметка водораздельной возвышенности составляет +198 м (в северозападной части месторождения). Относительное превышение её над урезом р. Селищной 24-26 м.

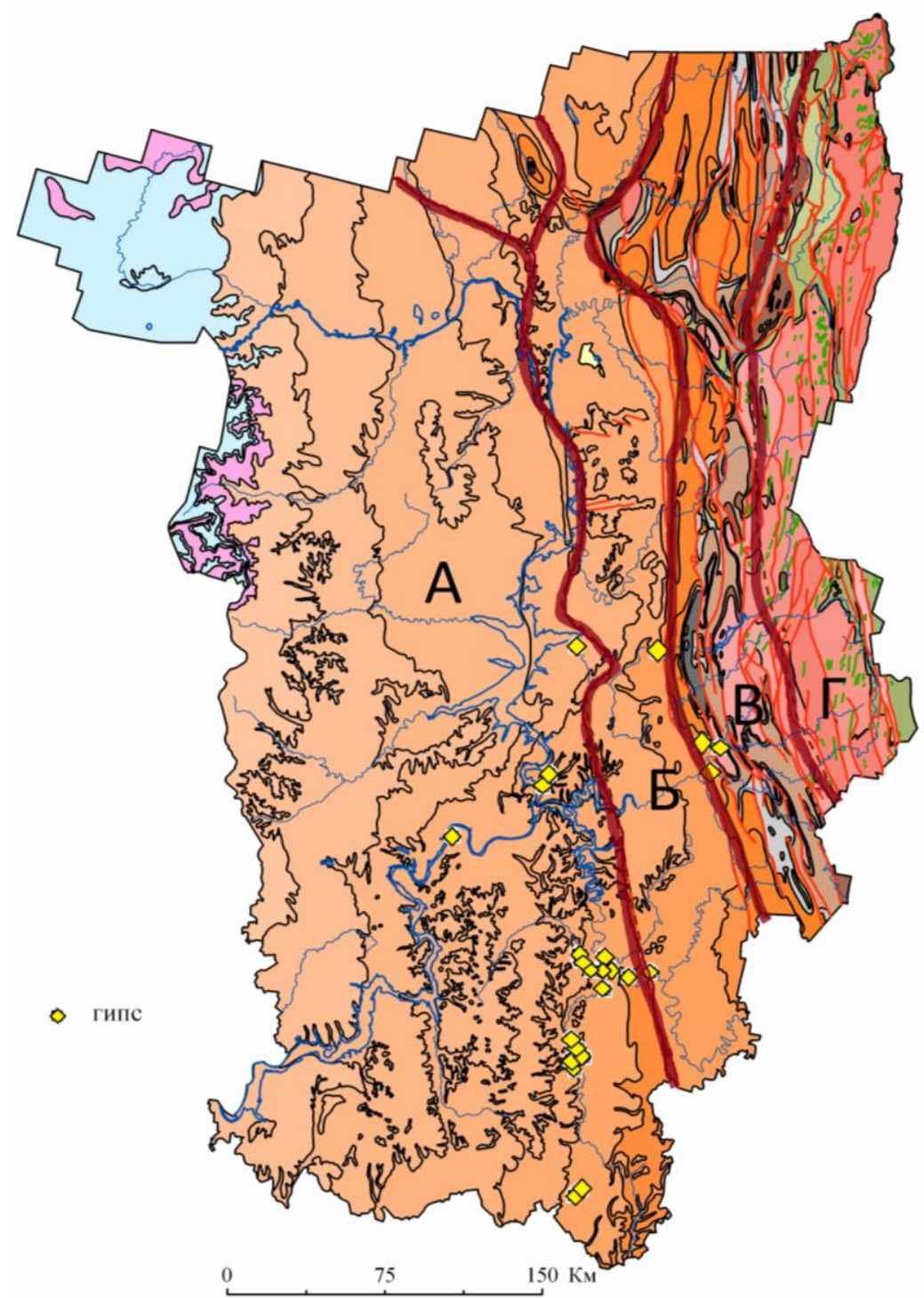

Рис. 1. Схема распределения месторождений гипса (Ибламинов, Алванян, 2010)

В геологическом отношении район месторождения характеризуется развитием осадочных образований девонского, каменноугольного и пермского возраста. Четвертичные отложения представлены элювиальными, делювиальными и аллювиальными рыхлыми отложениями. Месторождение - линзообразной залежью гипса среди известково-песчано-глинистых пород кунгурского яруса нижней перми.
Мощность гипсовой толщи изменяется от 5,0 до 20,5 м. Подстилающими гипс породами являются известковистые песчаники и алевролиты, переслаивающиеся с известково-глинистыми сланцами и известняками (рис. 3). С поверхности гипсы перекрыты делювиальными глинами. Мощность вскрышных пород колеблется от 0,1 до 11,7 м. 


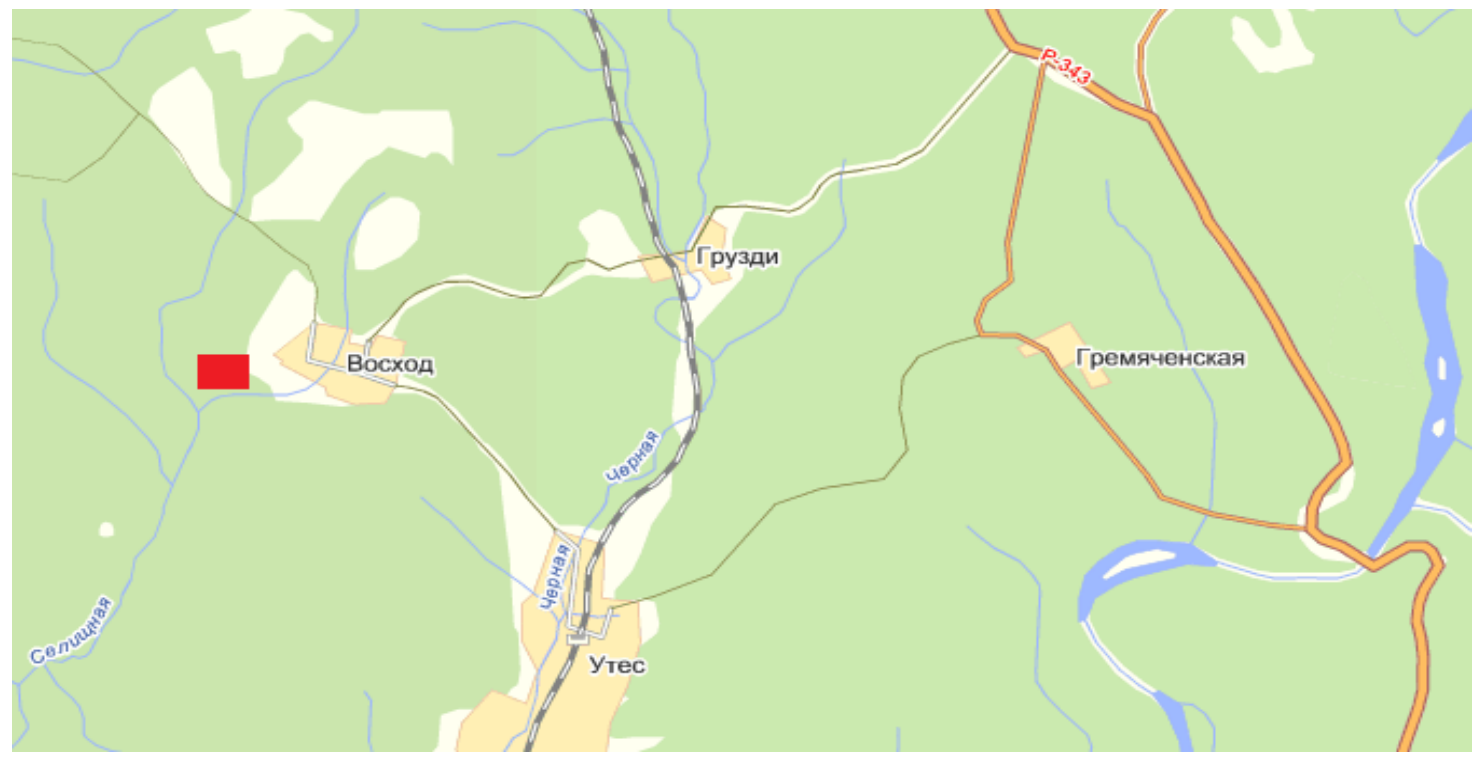

Рис. 2. Обзорная карта района работ

- Селищенское месторождение строчтельного гипса
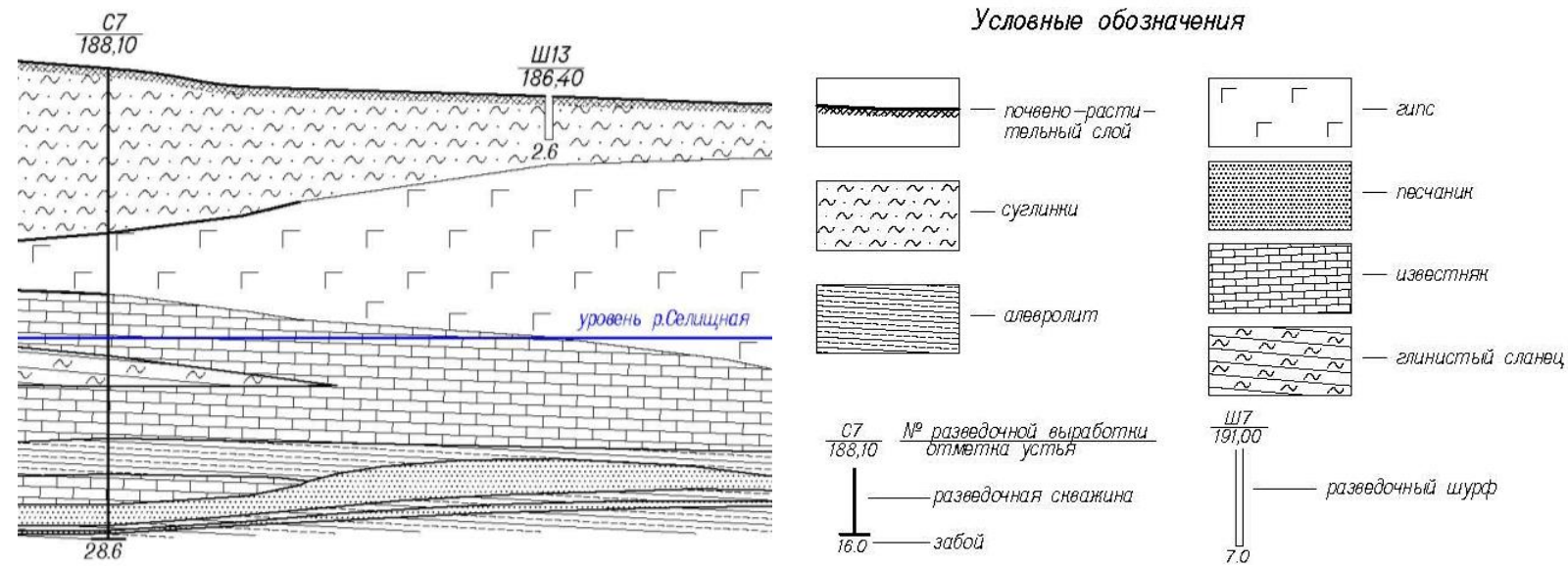

Рис. 3. Геолого-литологический разрез

Требования к химическому составу гипсового и гипсоангидритового камня по ГОСТ 4013-82

\begin{tabular}{|c|c|c|c|c|}
\hline \multirow[b]{2}{*}{ Сорт } & \multicolumn{2}{|c|}{$\begin{array}{c}\text { Содержание в гипсовом камне, \% } \\
\text { (не менее) }\end{array}$} & \multicolumn{2}{|c|}{$\begin{array}{c}\text { Содержание в гипсоангидритовом } \\
\text { камне, \% (не менее) }\end{array}$} \\
\hline & $\begin{array}{c}\text { гипса, } \\
\mathrm{CaSO}_{4} \cdot 2 \mathrm{H}_{2} \mathrm{O}\end{array}$ & $\begin{array}{c}\text { кристаллизационной } \\
\text { воды }\end{array}$ & $\begin{array}{c}\text { гипса и ангидрита } \\
\text { в пересчете } \\
\text { на } \mathrm{CaSO}_{4} \cdot 2 \mathrm{H}_{2} \mathrm{O} \\
\end{array}$ & $\begin{array}{c}\text { серного } \\
\text { ангидрита, } \mathrm{SO}_{3}\end{array}$ \\
\hline 1 & 95 & 19,88 & 95 & 44,18 \\
\hline 2 & 90 & 18,83 & 90 & 41,85 \\
\hline 3 & 80 & 16,74 & 80 & 37,20 \\
\hline 4 & 70 & 14,64 & - & - \\
\hline
\end{tabular}

Описываемая территория относится к провинции подземных вод восточной окраины Русской платформы. Здесь распространены поровые, трещинные и карстовые подземные воды.
Гипсовый камень по содержанию гипса и гипсоангидритовый камень по суммарному содержанию гипса и ангидрита в пересчете на гипс согласно ГОСТ 4013-82 подразделяют на сорта, указанные в таблице. Содержание гипса в гипсовом камне 
определяют по кристаллизационной воде, а в гипсоангидритовом камне - по серному ангидриту ( $\left.\mathrm{SO}_{3}\right)$. По химическому составу гипс Селищенского месторождения вполне отвечает требованиям промышленности. Из 52 имеющихся химических анализов в 38 (73\%) содержание $\mathrm{CaSO}_{4} \cdot 2 \mathrm{H}_{2} \mathrm{O}$ было более $90 \%$, (таблица).

\section{Мероприятия по охране недр}

В соответствии с положениями закона «О недрах» техническим проектом доработки месторождения предусмотрено наиболее полное извлечение и рациональное использование запасов полезного ископаемого с учетом требований охраны поверхностных и подземных вод от загрязнения.

Охрана недр заключается в проведении технического этапа рекультивации после отработки месторождения при строгом соблюдении границ горного отвода.

В связи с выемкой полезного ископаемого в пределах горной выработки после проведения технического этапа рекультивации создается достаточно ровная поверхность с потенциально плодородным слоем грунта из глинистых слабоводопроницаемых отложений, препятствующих развитию процесса карстообразования, и близкая по качественным характеристикам к естественным условиям до вскрытия месторождения.

Биологический этап рекультивации дополняет и ускоряет восстановление почвенно-растительного покрова и создает условия для естественного лесозарастания. Следовательно, охрана недр не требует проведения специальных мероприятий.

Оиенка воздействия на геологическую среду. Выемка продуктивных отложений оказывает непосредственное, постоянно сохраняющееся воздействие на геологическую среду, заключающееся в безвозвратном изъятии вещества. Это воздействие определяется целевым назначением объекта и является неизбежным следствием планируемых работ. Последствия воздействия локализованы, не распространяются за границы горного отвода и относятся к стабильным, не изменяющимся со временем. Локальность воздействия в связи с народно-хозяйственным назначением объекта можно считать допустимой.

Охрана земельных ресурсов. Площадь существующего земельного участка составляет 11,4 га. Охрана земельных ресурсов Селищенского месторождения заключается в строгом соблюдении границ горного отвода и земельного участка, в пределах которых предполагаются все нарушения земель. Нарушенные земли подлежат природоохранной рекультивации с элементами лесохозяйственного восстановления.

Загрязнение почвенного покрова химическими веществами и нефтепродуктами не предполагается в связи с концентрацией работ непосредственно в карьере.

Анализ многочисленной литературы (Карта, 1997; Вологжанина, 1999; Классификация, 1997; Данилова, 1969; Малеев, 1999; Малеев, Двинских, 2003; Овеснов, 1997; Колесников и др. 1969; Особо охраняемые..., 2002; Красная книга...,1996) позволил установить, что в границах рассматриваемой площади и в непосредственной близости от нее отсутствуют природные объекты, в том числе геоботанические, имеющие статус особо охраняемых резерватов, подлежащие охране редкие и исчезающие краснокнижные виды как на территории планируемого к разработке месторождения, так и на непосредственно примыкающей к нему. Не выявлено мест массового распространения лекарственных или хозяйственноценных растений, позволяющих проводить заготовку сырья.

Учитывая изложенное, можно заключить, что разработка месторождения с выполнением по мере ее завершения рекультивации не нанесет необратимого ущерба современному состоянию растительного покрова территории. В результате дополнительных мероприятий по охране земельных ресурсов не требуется. 
Мероприятия по охране поверхностных $u$ nодземных вод. Месторождение расположено за пределами водоохранных зон р. Селищная и ее притока. Водоотлив из карьера не предусмотрен, т. к. нижняя граница разработки карьера располагается выше горизонта подземных вод. Водопритоки в карьер формируются только за счет атмосферных осадков и снеготаяния. Боковая приточность отсутствует в связи с созданием земляных валов по бровке карьера. Интенсивная трещиноватость и закарстованность сульфатных пород месторождения способствуют быстрому просачиванию выпадающих атмосферных осадков и талых вод и исключают затопление карьера. Использование опасных или азональных химических веществ при разработке месторождения не предусматривается.

Твердые бытовые отходы собираются в металлический контейнер и вывозятся по разовым договорам на муниципальный полигон ТБО. Следовательно, загрязнения поверхностных и подземных вод не ожидается.

Охрана животного мира. По данным регионального мониторинга животный мир района размещения месторождения представлен 92 видами наземных позвоночных, являющихся в фаунистическом отношении обычными обитателями восточно-европейской провинции Бореального пояса.

Своеобразие фауны обусловлено размещением месторождения на стыке горной и равнинной тайги, в связи с чем состав зоокомплексов пестр. В составе зоокомплексов 8 видов животных относятся к охотничье-промысловым, имеющим хозяйственную ценность, однако в связи со значительной освоенностью территории из них реально встречается лишь 6 (Зиновьев и др., 2001; Шепель, 2002).

Редких и исчезающих (краснокнижных) представителей фауны в пределах отводимой площади не обнаружено. Од- нако по данным профессора А.И. Шепеля, территория входит в охотничью площадь некоторых хищных птиц: черного коршуна, полевого луня и др. (Красная книга .... 1996).

Bce млекопитающие относительно оседлы, пути миграции имеют местный характер, не связанный территориально с участком месторождения.

Водоемов, имеющих рыбопромысловое значение, на территории нет.

Редкие и особо охраняемые виды животных и птиц, включенные в Красную книгу и аналогичный список для Пермского края, отсутствуют.

Мероприятия по охране животного мира заключаются в следующем: начало работ не должно совпадать с репродуктивным периодом в жизни биоты, чтобы представители животного мира и пернатые обитатели территории не покинули потомство под влиянием беспокойства.

В целом воздействие на животный мир можно оценить как несущественное.

Рекультивация земель. Рекультивации подлежат: дно карьерной выработки, частично занятое водоёмом, откосы внешнего и внутреннего отвалов, площадь, занимаемая временным внешним отвалом, и подъездные дороги.

Учитывая вышеизложенное, согласно техническим условиям на рекультивацию нарушенных земель, нами приняты следующие положения проведения рекультивационных работ.

А. Направление рекультивации принять природоохранным с элементами лесохозяйственного восстановления нарушенных земель.

Б. На дне карьера и на поверхностях отвалов организовать насаждение ели сибирской трехрядное - в полосах шириной 11 м с промежутками 9 м по схеме $3 \times 1$. На бровке откоса высадить шиповник с промежутком в 1 м между кустами. На площадях откосов сформированных отвалов гидропосев многолетних трав. 




Рис. 4. План рекультивированного карьера

Условные обозначения

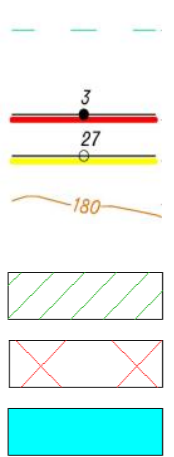

- охранная зона реки согласно Водному кодексу РФ № 87-ФЗ в ред. от 07.05.2013

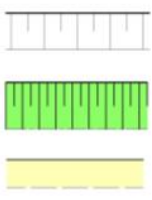

- нерекультивируемый откос карьерной выемки

- линия горного отвода

- рекультивируемый откос отвала, засаженный многолетними травами

- граница земельного участка

- изолинии земной поверхности

- внутрикарьерная технологическая

дорога

- участок горной выработки, заполненный глиной

- участок земной поверхности с восстановленным почвенно-растительным слоем

- участок горной выработки, заполненный водой

На площади откосов добычных уступов рекультивация не предусматривается ввиду большого уклона $\left(65^{\circ}\right)$ и невозможности организовать нанесение плодородного слоя на каменную (гипсовую) основу.

В целях исключения падения животных и людей в карьерную выемку преду- смотрено создание защитной живой изгороди из колючих кустарников по бровке откоса карьера. Этот вид работ имеет непосредственное рекультивационное значение, закрепляет бровку выемки, препятствует развитию эрозионных процессов. План рекультивированного карьера приведен на рис. 4. 
Заключение. Анализ предлагаемых проектных решений и мероприятий по охране компонентов окружающей среды позволяет сделать вывод о их достаточности для процесса эксплуатации карьера и сохранения благоприятных экологических условий.

Отработка полезного ископаемого будет вестись открытым способом двумя уступами. Выемке горной массы предшествует рыхление буровзрывными работами. Погрузка производится экскаватором в автосамосвалы с последующей транспортировкой на дробильно-сортировочный завод (г. Пермь).

Оценка воздействия на окружающую среду разработки Селищенского месторождения показывает, что предлагаемые природоохранные мероприятия обеспечивают экологическую безопасность, их воздействие не распространяется за границы земельного участка и относится к стабильным, не изменяющимся со временем. Последовательное выполнение мероприятий и надлежащий авторский надзор соответствуют основным требованиям природоохранного законодательства Российской Федерации.

Анализ материалов позволил сделать вывод о допустимости ожидаемых в процессе эксплуатации месторождения воздействий на окружающую среду.

\section{Библиографический список}

Бейтс Р.Л. Геология неметаллических полезных ископаемых. М.: Мир, 1965. 547 с.

Вологжанина T.B. Почвы // Атлас Пермской области. М., 1999.

Данилова М.М. Геоботаническое районирование Пермской области// Леса СССР. М., 1969.
Даровских Н.А., Кудряшов А.И. Геология и поиски месторождений поделочного гипса / ГИ УрО РАН. Пермь, 2001. 161с.

Зиновьев Е.А., Шепель А.И. и др. Животный мир Пермской области. М., 2001.

Ибламинов Р.Г, Алванян А.К. Региональная минерагения общераспространенных полезных ископаемых зоны сочленения Восточно-Европейской платформы и Уральской складчатой области (на примере Пермского края) // Вопросы современной науки и практики / УН-т им. В.И. Вернадского. 2009. Вып. 9. С. 152 - 161.

Ибламинов Р.Г., Алванян А.К. Минерагеническая зональность общераспространенных полезных ископаемых Пермского края // Геология и полезные ископаемые Западного Урала: матер. регион. науч.-практ. конф. / Перм. гос. ун-т. Пермь, 2010. С. 96-98.

Карта почвенно-экологического районирования Восточно-Европейской равнины. М 1:2500000 / В.Г. Добровольский и др. М., 1997.

Классификация почв России / В.Д. Тонконогов и др. М., 1997.

Колесников Б.П. и др. Леса Пермской области // Леса СССР. М., 1969.

Красная книга Среднего Урала. Екатеринбург, 1996.

Малеев К.И. Растительность // Атлас Пермской обл.: географ. история. М., 1999.

Малеев К.И., Двинских С.А. Экологическое краеведение. Пермская область. Пермь, 2003.

Минерально-сырьевые ресурсы Пермского края: энциклопедия / под ред. А.И. Кудряшова. Пермь: Книжная площадь, 2006. $463 \mathrm{c}$.

Овеснов С.А. Конспект флоры Пермской области. Пермь, 1997.

Особо охраняемые природные территории Пермской области: реестр. / отв. ред. С.А. Овеснов. Пермь, 2002.

Шепель А.И. Справка о состоянии животного мира районов Пермской области. Пермь, 2002. 


\title{
Mitigation the Environmental Problems
} of Operation of the Selishchenskoe Construction Gypsum Deposit

\author{
A.K. Alvanian", R.G. Iblaminov ${ }^{a}$, K.A. Tamoyan , A.A. Sogorin \\ aPerm State University. 15 Bukireva Str., Perm 614990, Russia. E-mail: iqeon@psu.ru \\ ${ }^{b}$ LLC UralGeoProekt. 3/7 Revolutsii Str., Perm 614007, Russia. \\ E-mail: Geo.progekt@yandex.ru
}

The issues of protection of soils, land resources, atmospheric air, flora and fauna, surface and groundwaters and restoration (reclamation) of disturbed lands are considered. Measures have been developed to reduce and prevent the negative impact on the environment by the development of the open pit mineral deposits.

Key words: gypsum deposits, environmental protection measures, reclamation, Perm

Kray.

\section{References}

Bates R.L. 1960. Geology of the industrial rocks and minerals. New York, Harper \& Brothers, p. 441.

Vologzhanina T.V. 1999. Pochvy [Soils]. In Atlas Permskoy oblasti. Moskva. (in Russian)

Danilova M.M. 1969. Geobotanicheskoe rayonirovanie Permskoy oblasti [Geobotanical zoning of the Perm region]. In Lesa SSSR. Moskva. (in Russian)

Darovskikh N.A., Kudryashov A.I. 2001. Geologiya i poiski mestorozhdeniy podelochnogo gipsa [Geology and prospecting of gypsum deposits]. GI UrO RAN, Perm, p. 161. (in Russian)

Zinoviev E.A., Shepel A.I. et al. 2001. Zhivotnyy mir Permskoy oblasti [Animal World of the Perm Region]. Moskva.

Iblaminov R.G., Alvanyan A.K. 2009. Regionalnaya minerageniya obshcherasprostranennykh poleznykh iskopaemykh zony sochleneniya Vostochno-Evropeyskoy platformy i Uralskoy skladchatoy oblasti (na primere Permskogo kraya) [Regional minerageny of common minerals in the boundary between East European Platform and Urals folding region (on the example of Perm Kray)]. Voprosy sovremennoy nauki i praktiki. 9:152161. (in Russian)

Iblaminov R.G., Alvanyan A.K. 2010. Mineragenicheskaya zonalnost obshcherasprostranennykh poleznykh iskopaemykh Permskogo kraya [Mineragenic zonation of common minerals of the Perm Kray]. In Geologiya i poleznye iskopaemye Zapadnogo Urala. Mater. of sci. conf. PSU, Perm, pp. 96-98.
Karta pochvenno-ekologicheskogo rayonirovaniya Vostochno-Evropeyskoy ravniny. Mashtab 1:2500000 [Map of soil-ecological zoning of the East European Plain. Scale 1: 2500000]. Eds. V.G. Dobrovolskiy et al. 1997. Moskva. (in Russian)

Klassifikatsiya pochv Rossii [Classification of soils of Russia]. Eds. V.D. Tonkonogov et al. 1997. Moskva. (in Russian)

Kolesnikov B.P. et al. 1969. Lesa Permskoy oblasti [Forests of the Perm region]. Lesa SSSR. Moskva. (in Russian)

Krasnaya kniga Srednego Urala [Red Book of the Middle Urals]. 1996. Ekaterinburg. (in Russian)

Maleev K.I. 1999. Rastitelnost [Vegetation]. In Atlas Permskoy oblasti. Moskva. (in Russian)

Maleev K.I., Dvinskikh S.A. 2003. Ekologicheskoe kraevedenie. Permskaya oblast [Ecological study of local area. Perm region]. Perm.

Mineralno-syryevye resursy Permskogo kraya: entsiklopediya [Mineral and raw materials resources of the Perm Kray: Encyclopedia]. Ed. A.I. Kudryashova. 2006. Perm, Knizhnaya ploshchad, p. 463. (in Russian)

Ovesnov S.A. 1997. Konspekt flory permskoy oblasti [Abstract of the flora of the Perm Region]. Perm. (in Russian)

Osobo okhranyaemye prirodnye territorii Permskogo kraya: reestr [Protected natural areas of the Perm region: the register]. $E d$. S.A. Ovesnov. 2002, Perm. (in Russian)

Shepel A.I. 2002. Spravka o sostoyanii zhivotnogo mira rayonov Permskoy oblasti [Information about the state of wildlife in the Perm region]. Perm. (in Russian) 